\title{
UM BREVE OLHAR PARA A BNCC, AS TECNOLOGIAS DIGITAIS E A PRODUÇÃO TEXTUAL NO ENSINO MÉDIO ${ }^{1}$
}

\author{
Fernanda de Quadros Carvalho Mendonça* \\ Claudia Vivien Carvalho de Oliveira Soares**
}

RESUMO: A cibercultura é uma realidade que cada dia mais faz parte da nossa sociedade transformando-a constante e rapidamente. Sendo assim, a inserção das tecnologias digitais no fazer pedagógico e no ambiente escolar se faz necessária de maneira que permita ao aluno a construção do conhecimento baseado em práticas colaborativas. O presente texto tem o objetivo de apresentar uma breve análise em torno das diretrizes constante na Base Nacional Curricular Comum, doravante BNCC, no tocante ao uso das tecnologias digitais na sala de aula, focalizando a produção textual no ensino médio. De cunho qualitativo, este trabalho caracteriza-se na perspectiva da pesquisa documental e de estudos teóricos à luz de autores como Alves (1998), Bohn (2013), Lévy (2010) e Marcuschi, (2004). Os resultados nos indicam que a BNCC preconiza que as tecnologias digitais sejam assumidas como um elemento relevante para elaboração de novas práticas pedagógicas.

PALAVRAS-CHAVE: BNCC; Produção Textual; Tecnologias digitais.

\section{Introdução}

O século XXI tem seu início marcado pelo avanço tecnológico e uma significativa mudança na área da comunicação. Lévy (2010), no final da década de 1990, já sinalizava que haveria uma transformação na forma de se comunicar impulsionada pelos avanços da Internet. Percebemos que esse avanço permitiu e imprimiu novos delineamentos à nossa comunicação, elaborando concepções de interação que extrapolam o emprego tradicional

\footnotetext{
${ }^{1}$ Este artigo é um recorte da dissertação "Tecnologias digitais na sala de aula:reflexões sobre a aprendizagem de produção textual” do Programa de Pós-Graduação em Letras:Cultura, Educação e Linguagens (PPGCEL); Universidade Estadual do Sudoeste da Bahia (UESB);Vitória da Conquista; Bahia

* Mestranda em Letras: Cultura, Educação e Linguagens pela Universidade Estadual do Sudoeste da Bahia (Uesb). Bolsista da Fundação de Amparo à pesquisa do Estado da Bahia (Fapesb).

** Doutora em Letras pela Universidade Federal da Bahia (Ufba). Professora Titular na Universidade Estadual do Sudoeste da Bahia (Uesb).
} 
da linguagem escrita, porém não restringe sua relevância para o cenário social atual. A cibercultura é uma realidade recente que cada dia mais faz parte da nossa sociedade transformando-a constante e rapidamente.

Já em relação à produção textual, vimos o surgimento de diversos gêneros advindos das tecnologias digitais e o desenvolvimento de uma, digamos, "escrita eletrônica" (MARCUSCHI, 2004). Dessa maneira, a inserção das tecnologias digitais no fazer pedagógico e no ambiente escolar se faz necessário de maneira que permita ao aluno a construção do conhecimento baseado em práticas colaborativas.

Diante dessas mudanças, no intuito de regular o ensino no Brasil, baseado na Constituição Federal e outros documentos oficiais, o governo federal publica em 2018 a versão definitiva da BNCC e nela encontramos uma tentativa de incluir no fazer pedagógico o trabalho com as tecnologias digitais reconhecendo as mudanças ocorridas na contemporaneidade.

Em consonância com a BNCC, é função da escola incorporar em sua comunidade escolar práticas pedagógicas que permitam a aproximação com o mundo atual já que esta é uma das agências de letramento de relevância no meio social (MENDONÇA; SOARES, 2018, 2019). Segundo Mendonça e Soares $(2018,2019)$ a escola reúne condições para proporcionar ao aluno a possibilidade de dialogar, de se expressar em diferentes linguagens, a fim de desenvolver as competências requeridas para o século XXI. Isto posto, o presente estudo tem o objetivo de apresentar uma breve análise em torno das diretrizes constante na Base Nacional Curricular Comum, doravante BNCC, no tocante ao uso das tecnologias digitais na sala de aula, focalizando a produção textual no ensino médio.

Nesse sentido, apresentaremos considerações em torno das tecnologias digitais na contemporaneidade no intuito de discutir possibilidades educacionais que surgem com o advento da cibercultura, focalizando a importância da produção textual nesse cenário e, por fim, os impactos que as orientações da BNCC trazem para as práticas pedagógicas contemporâneas. 


\section{Tecnologias digitais na contemporaneidade}

Iniciamos esta seção lembrando que o novo, a novidade, aquilo que não dominamos é temido; assim, não seria diferente com o avanço tecnológico que estamos vivenciando.

De acordo com Dudeney, Hockly e Pegrum (2016), “o advento das tecnologias trouxe a necessidade de novos letramentos, novas competências para que possamos participar dessa sociedade pós-industrial digitalmente conectada" (DUDENEY; HOCKLY; PEGRUM, 2016, p. 17). Nesse sentido, é possível assegurar que todas as vezes que mudamos a nossa forma de produzir informação aconteceu uma revolução e hoje estamos em busca da compreensão da mais rápida revolução da comunicação da humanidade.

Estamos inseridos na cibercultura, produzimos e distribuímos informações de maneira planetária, em vários gêneros e livremente. Antes de prosseguir, é preciso registrar que adotamos a definição de Lévy (2010) de ciberespaço (novo meio de comunicação que surge da interconexão mundial dos computadores) e cibercultura (conjunto de técnicas, práticas, de atitudes, de modos de pensamentos e de valores desenvolvidos no ciberespaço) (LÉVY, 2010, p. 17).

Sabemos que a internet modificou a nossa forma de aprender e de acessar a informação, consequentemente ocorreu uma mudança também da nossa relação com o saber. Anteriormente, através da educação, o aluno tinha acesso à informação e o caminho para o aprendizado era direcionado pelo professor. Hoje, a informação chega de todas as maneiras e é preciso ter um olhar crítico sobre elas. Precisamos aprender a navegar nesse novo território que tem seu tempo e espaço diferentes do nosso, numa velocidade de mudança que muitas vezes não alcançamos. Em relação à velocidade em que estamos imersos na contemporaneidade, Lévy (2010) relata que ela é uma constante paradoxal da cibercultura e isso é o que explica a sensação de estranhamento e impacto que se apresenta sempre, pois tentamos compreender esse movimento. Para o autor:

A aceleração é tão forte e tão generalizada que até mesmos os mais "ligados" encontram-se, em graus diversos, ultrapassados pela mudança, já que ninguém pode participar ativamente da criação das transformações do conjunto de especialidades técnicas, nem mesmo seguir essas transformações de perto. (LÉVY, 2010, p. 28) 
Segundo Santaella (2014), mesmo diante das mutações que o universo digital estava fadado a trazer para os ambientes escolares, durante todo o século XX, a educação permaneceu fiel à sua hegemonia gutenberguiana. O livro, as apostilas, enfim, o texto impresso, aliado à fala do professor, todos eles cumpriam sua função de transmissão privilegiada do saber.

A mudança na lógica da forma de acesso ao conhecimento tem nos requeridos posturas diferenciadas diante da transmissão e construção do saber, e a escola deve ser o lugar da mudança para que ela continue a existir. Portanto, desponta a necessidade de "uma ruptura com o ensino e a aprendizagem estruturada" (BOHN, 2013), pois, conforme dito anteriormente, a maneira de aprender mudou, temos uma aprendizagem mais colaborativa e a tela nos proporciona uma experiência diferente, sem muita linearidade.

Precisamos preparar os alunos para a vida social e para o emprego em um mundo digitalmente conectado. Contudo, sabemos que algumas habilidades e competências requeridas pelo mercado de trabalho e pelo mundo globalizado são próprias do século XXI. Assim sendo, Dudeney, Hockly e Pegrum (2016, p. 17) destacam algumas que julgam necessárias para atender as demandas da atualidade, a saber: criatividade e inovação, pensamento crítico e capacidade de resolução de problemas, colaboração e trabalho em equipe, autonomia e flexibilidade, aprendizagem permanente e a capacidade de se envolver com as tecnologias digitais. Dessa maneira, é preciso que nos apropriemos delas para que, assim, consigamos participar mais ativamente da atualidade.

O desenvolvimento dos letramentos digitais, definido por Dudeney, Hockly e Pegrum (2016, p. 17) como "habilidades individuais e sociais necessárias para interpretar, administrar, compartilhar e criar sentido eficazmente no âmbito crescente dos canais de comunicação digital", é um dos caminhos possíveis para inserção das tecnologias digitais na sala de aula. Não perdendo de vista que, antes de tudo, é preciso que desenvolvamos nos alunos a capacidade crítica para a utilização da internet, no intuito de ampliação do seu uso, afastando-os da ideia de que esta é apenas um canal de entretenimento.

$\mathrm{Na}$ contemporaneidade, "novos suportes digitais impulsionam novas manifestações linguísticas e nos proporcionam diferentes práticas sociais" (MENDONÇA; SOARES, 
2018, p. 1110). Dessa maneira, precisamos reconhecer os novos modos, os novos eventos de letramentos e integrá-los à nossa prática diária. Buscar a promoção de um ensino baseado no desenvolvimento das diversas competências exigidas para esse novo século, a fim de preparar o aluno para a vida social, para o emprego, em um mundo digitalmente conectado.

Sendo assim, na seção seguinte discutiremos o ensino da produção textual no contexto atual.

\section{Ensino da produção textual na contemporaneidade}

Atualmente, escrever passou a ser um elemento crucial de interação. Para Elias (2011), as novas práticas de escrita que surgiram com o advento da internet, no ambiente virtual, merecem reflexão por parte de nós pesquisadores, pois, conforme afirma:

Se houve um tempo em que era comum se ouvir dizer que os alunos de modo geral não gostavam de escrever e quando o faziam era para atender a alguma solicitação da escola, atualmente, essa afirmação está cada vez mais difícil de ser sustentada, visto que, em tempos de cultural digital, os alunos trocam muitas mensagens na internet, criam comunidades virtuais, blogam, twittam no universo da rede, interagindo com várias e várias pessoas por meio da escrita e sem que a escola solicite que eles o façam [...] (ELIAS, 2011, p. 159).

Conforme Barton e Lee (2015), “a escrita se torna cada vez mais importante na vida contemporânea" e "as novas tecnologias são o veículo dessa mediação textual” (BARTON; LEE, 2015, p. 30).

Santos (2018), destaca que se trata

[...] de um momento da história da humanidade marcado, principalmente, pela reconfiguração de práticas e de modalidades midiáticas, pela desterritorialização e virtualização dos saberes e pela conectividade global [do qual] emergem, evidentemente, novas formas de relação com o conhecimento e novos modos de organização da linguagem. (SANTOS, 2018, p. 57) 
Dito isto, acreditamos que na contemporaneidade temos a nosso favor as tecnologias digitais, que, quando utilizadas adequadamente, podem ampliar as competências linguísticas dos nossos alunos, mas, para isso, é preciso saber como e quais os recursos a serem utilizados para a ampliação desse repertório.

É importante destacar que a BNCC (BRASIL, 2018) entende competência como a mobilização de conhecimentos, habilidades, atitudes e valores para que o estudante esteja apto a resolver as demandas do cotidiano, do exercício da cidadania e do mundo do trabalho.

Na BNCC, competência é definida como a mobilização de conhecimentos (conceitos e procedimentos), habilidades (práticas, cognitivas e socioemocionais), atitudes e valores para resolver demandas complexas da vida cotidiana, do pleno exercício da cidadania e do mundo do trabalho. (BRASIL, 2018, p. 10)

$\mathrm{Na}$ base, a orientação por competências acaba indicando à escola e ao estudante o que deve ser aprendido e com que finalidade a competência deve ser desenvolvida e isso pode reduzir a competência a um caráter individual, como definem Marinho-Araújo e Almeida:

O desenvolvimento de competências, focando apenas habilidades ou estruturas cognitivas, que o sujeito mobiliza diante de seus objetivos e potencialidades, reduz a concepção de competências a uma característica individual, treinável, sem implicar um caráter coletivo à combinação de competências requeridas por um contexto profissional específico ou uma determinada categoria profissional. (MARINHO-ARAUJO; ALMEIDA, 2017, p. 3)

Assim ressaltamos que compreendemos que para o desenvolvimento da escrita precisamos mobilizar alguns conhecimentos. Dessa forma, necessitamos adotar a noção de competência que esteja ancorada "na mobilização intencional de diversos recursos próprios ao desenvolvimento humano: processos psicológicos, comportamentos, conhecimentos, afetos, crenças, habilidades, escolhas éticas e estéticas, que devem ser mobilizados pelo sujeito” (MARINHO-ARAUJO; ALMEIDA, 2017, p. 1), para que, assim, tenhamos um terreno "fértil de mediação permanente e recursiva entre a construção do saber e a ação social cotidiana” (MARINHO-ARAUJO; ALMEIDA, 2017, p. 4). Com base em Vygotsky 
(1991), o ser humano é resultado de suas interações no contexto social e cultural. Em relação ao aprendizado, ele ressalta que

[...] o aprendizado desperta vários processos internos de desenvolvimento, que são capazes de operar somente quando a criança interage com pessoas em seu ambiente e quando em operação com seus companheiros. Uma vez internalizados, esses processos tornam-se parte das aquisições do desenvolvimento independente da criança. (VYGOTSKY, 1991, p. 60-61)

Diante disso, reafirmamos que a interação é condição essencial para o desenvolvimento da escrita. Que a linguagem faz parte da constituição dos sujeitos, que é por ela que estes se inserem no mundo, que ela é o elemento comum que promove a interação em uma sociedade, decorrendo disso toda a dimensão e importância em compreender as suas relações e interações.

Salientamos, em consonância com Brito (1983), que a língua é o instrumento mais utilizado para interação humana. O autor ratifica essa ideia ressaltando a importância de se ter sempre um interlocutor. Ele enfatiza que "a língua é o meio privilegiado de interação entre os homens. Em todas as circunstâncias em que se fala ou se escreve há um interlocutor" (BRITO, 1983, p. 151).

Bunzen (2006), então, assevera que "aprende-se a escrever na relação com o outro, atualizando formas relativamente consagradas de interação linguística. Aprende-se a escrever por meio da interação verbal e do uso dos gêneros" (BUNZEN, 2006, p. 158). Dessa forma, tomando a escrita como uma atividade funcional, uma ação orientada, precisamos determinar e ensinar a esse aluno a finalidade para a escrita. Ensinar a expressar a intenção, o propósito, precisamos demonstrar a finalidade de se escrever para informar, narrar, definir, explicar, suscitar reflexões (ANTUNES, 2016).

Sabemos que o Ensino Médio é a etapa final da educação básica, período que os alunos terão para consolidar e aprofundar todo o conhecimento do Ensino Fundamental, conforme preconiza a BNCC (2018). Todavia, Emediato (2016) afirma que "vários anos de estudo de Língua Portuguesa na educação básica não foram suficientes para a formação 
do aluno para a expressão escrita e nem para seu desempenho como leitor" (EMEDIATO, 2016, p. 144) e complementa esse pensamento da seguinte maneira:

[...] com efeito, parte do problema se deve à concepção de escrita $\mathrm{e}$ de leitura ainda bastante reduzida aos aspectos formais do sistema linguístico, ou seja, à gramática e à correção ortográfica, e a uma didática estrutural e reprodutivista que não se coaduna como didática para o pensamento crítico. (EMEDIATO, 2016, p. 144)

Mendonça e Soares (2018), pautadas em Bunzen (2006), Marchuschi (2002), compreendem que para o desenvolvimento dessa escrita, sob os aspectos interacionais e sociais, devemos demonstrar aos estudantes os diversos gêneros textuais existentes, bem como desenvolver suas competências em escrita através desses gêneros.

Contudo, compreendemos que, para a efetivação de um fazer pedagógico consciente, o professor precisa, primeiramente, ter definida de maneira clara qual a sua concepção de linguagem. Para nós é na concepção interacionista, em que a linguagem é vista como um lugar de interação, espaço onde se constituem as relações sociais, que consegue atender as novas demandas sociais. Essa concepção de linguagem propicia um ensino de língua portuguesa baseado em textos e na diversidade de gêneros, pois, segundo Bakhtin ([1979] 1997), a língua se materializa em textos e estes em gêneros, no momento em que ocorre a interação e a comunicação acontece. Assim, sustentamos, para o desenvolvimento da escrita sob os aspectos interacionais e sociais, que devemos demonstrar ao aluno os diversos gêneros textuais existentes, bem como desenvolver suas competências em escrita através desses gêneros advindos das novas tecnologias.

O trabalho do professor pode "despertar no aluno a consciência da importância social que tem sua escrita, e que o texto é o meio pelo qual se realiza a sua comunicação nas diversas esferas" (MENDONÇA; SOARES, 2018, p. 1113). Acreditamos que, dessa maneira, o aluno passará a escrever com vistas a melhorar suas habilidades e cumprir seu objetivo comunicativo. A escrita é uma atividade que exige dos alunos um percurso a ser construído baseado nas suas leituras, nas informações que eles têm acesso e nas reflexões que são realizadas por eles ao ativarem seu conhecimento de mundo. É relevante estimular 
o nosso aluno a desenvolver sua capacidade crítica para desenvolvimento da produção escrita, já que os textos circulam socialmente e compõem o processo de interação. Devendo esses textos serem legitimados pela escola com projetos constituídos de recursos metodológicos que privilegiem tal legitimação.

Concordamos com Borges da Silva (2019), quando ela discute que "ensinar a língua escrita no contexto escolar tem se mostrado um grande desafio aos professores de português" (BORGES DA SILVA, 2019, p. 191), pois sabemos, assim como ela destaca, que "a contemporaneidade demanda considerar a língua enquanto substância” (BORGES DA SILVA, 2019, p. 191), exigindo que deixemos, de uma vez por todas, de pensar a língua somente nos aspectos de seu funcionamento formal.

Por ora, lembremos que para Bakhtin (1981), conforme ressalta Silva (2015), “a língua está diretamente relacionada às atividades humanas, e estas estão em constante processo de mudança e renovação, fazendo com que surjam novos gêneros para atender às novas práticas comunicativas" (SILVA, 2015, p. 15).

Ademais, "a escola não deve ignorar o surgimento de diversos gêneros discursivos advindos das tecnologias digitais" (MENDONÇA; SOARES, 2018, p. 1111). A escola pode diligenciar os debates sobre tecnologias, ser o espaço de acesso do aluno na sociedade e assim contribuir para o processo formativo de sua comunidade nesses novos letramentos. Ribeiro (2016) afirma que "a escola é considerada a agência principal onde se dá a formação de conceitos diretamente ligados ao exercício da cidadania” (RIBEIRO, 2016, p. 44), em consonância com o que acreditamos.

Segundo Pretto (2014), a escola deve compreender o momento atual. Para isso o autor recomenda que a escola se transforme, com a "implantação de um ecossistema pedagógico de aprendizagem e de produção de culturas e conhecimentos" (PRETTO, 2014, p. 348).

De acordo com Hetkowski e Menezes (2019), a escola pode apresentar maneiras de instigar as crianças a compreenderem criticamente o mundo contemporâneo, sendo, para isso, preciso desenvolver nos alunos competências e habilidades que os capacitem "a 
interagir com outras linguagens, com outras modalidades de textos" (HETKOWSKI; MENEZES, 2019, p. 218). Para tanto, precisamos que a escola legitime as novas práticas de leitura e de produção de textos, a fim de que façam parte do cotidiano dos alunos, nos diversos espaços de socialização, tanto orais quanto escritos (MENDONÇA; SOARES, 2018, p. 1112). E o primeiro passo é não ignorar o surgimento de diversos gêneros advindos das tecnologias digitais, e sim proporcionar uma inserção das tecnologias no ambiente escolar.

Sendo assim, passaremos à seção seguinte, na qual apresentaremos algumas considerações em torno das orientações da BNCC, em relação ao uso das tecnologias digitais na sala de aula, focalizando o aprendizado da produção textual, no Ensino Médio.

\section{A BNNC, as tecnologias digitais e a produção textual no Ensino Médio}

$\mathrm{Na}$ introdução da versão final do documento está posto que o texto da BNCC (2018) atende à determinação de um conjunto de documentos oficias que orientam a educação no Brasil, a saber: a Constituição Federal de 1988, a Lei de Diretrizes e Bases da Educação Nacional (LDB, Lei no 9.394/1996), o Plano Nacional de Educação (PNE) e as Diretrizes Curriculares Nacionais da Educação Básica (DCN).

Sendo a BNCC um documento normativo, de acordo com Mendonça e Soares (2019), encontraremos nela a definição dos parâmetros para a preparação dos currículos e propostas pedagógicas, com a finalidade de assegurar a todos os alunos da Educação Básica que é composta por três etapas (Educação Infantil, Ensino Fundamental e Ensino Médio), o desenvolvimento de um conjunto de conhecimentos, competências e habilidades necessárias para seu processo formativo na condição de cidadão.

A BNCC deve ser a referência para construção e revisão das propostas pedagógicas das instituições educacionais brasileiras em todos os níveis da Educação Básica e para tal o documento se divide explicitando as competências e habilidades específicas a serem desenvolvidas em cada etapa da Educação Básica. De acordo com Cury, Reis e Zanardi (2018), "a BNCC traz uma concepção de currículo travestida de direitos de aprendizagens" (CURY; REIS; ZANARDI, 2018 p. 66), já que tem a pretensão de prescrever "uma série 
de conteúdos idênticos para possibilitar uma igualdade de oportunidades entre os educandos" (CURY; REIS; ZANARDI, 2018, p. 61), ignorando as particularidades e necessidades locais de atores que estão envolvidos com a educação.

Ainda na introdução da BNCC, encontraremos um resumo da descrição das etapas da Educação Básica que têm sua estrutura detalhada (ao longo do documento) indicando o que deve ser desenvolvido em cada nível da escolarização. Salientamos que é nas descrições das habilidades que estão descritas um conjunto de aprendizagens essenciais que garantem o desenvolvimento das competências específicas de cada etapa.

Em relação ao Ensino Médio, visualizaremos, na Figura 1, que a etapa está organizada em quatro áreas do conhecimento, a saber: Linguagens e suas Tecnologias, Matemática e suas Tecnologias, Ciências da Natureza e suas Tecnologias e Ciências Humanas e Sociais Aplicadas. Posteriormente, as áreas se desdobram nas competências específicas e suas habilidades, que constituem a formação geral básica que deve estar articulada com os itinerários formativos (BRASIL, 2018, p. 470).

Figura 1 - Divisão da etapa do Ensino Médio

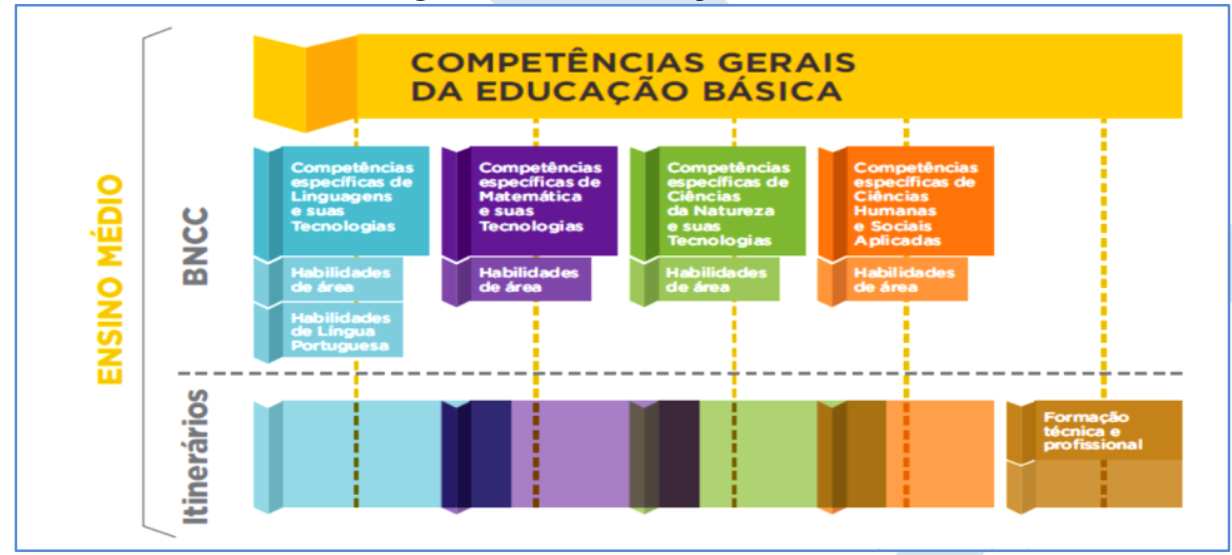

Fonte: BNCC (BRASIL, 2018, p. 469).

É importante ressaltar que, conforme a BNCC (2018), os itinerários devem ser construídos pelos diferentes sistemas, redes e escolas (BRASIL, 2018, p. 469). Todavia, Lopes (2019) pontua que a proposta dos itinerários "não é inédita na história do currículo 
e faz parte de discursos que tentam propor a individualização do percurso formativo em nome de uma pedagogia diferenciada" (LOPES, 2019, p. 66). A autora explica que este conceito traz a propositura da flexibilização da formação.

[‥] os itinerários formativos são concebidos como roteiro de estudos em um plano de formação continuada e como percursos formativos que o estudante poderá cursar no interior de processos regulares de ensino, possibilitando sua qualificação para fins de exercício profissional e/ou prosseguimento de estudos. Desse modo, é proposta a flexibilização da formação, no sentido de favorecer organizações curriculares diferentes nas instituições de educação profissional que possibilitem o reconhecimento de saberes e a certificação de atividades profissionais desenvolvidas em sistemas formais e nãoformais. (LOPES, 2019, p. 66)

A flexibilização da formação do ensino médio sofre críticas de autores como Silva (2018), que demonstram nos seus estudos que essa medida desenhada pela BNCC, e que foi imposta pela a publicação da Medida Provisória 746/16, que trata da "reforma do ensino médio", trará o esvaziamento da etapa devido à complexidade da realidade escolar brasileira e aumentará as desigualdades existentes ao prescrever conteúdo. Vale ressaltar que esta medida provisória tornou-se a lei no 13.415 , de 16 de fevereiro de 2017.

Abaixo, no Quadro 1, visualizaremos o resumo da estrutura de organização do Ensino Médio:

Quadro 1 - Resumo da estrutura de organização do Ensino Médio

\begin{tabular}{|c|c|c|c|}
\hline $\begin{array}{c}\text { Áreas do } \\
\text { Conhecimento }\end{array}$ & $\begin{array}{l}\text { Componentes Obri- } \\
\text { gatórias }\end{array}$ & $\begin{array}{l}\text { Componentes } \\
\text { complementares }\end{array}$ & Habilidades \\
\hline $\begin{array}{l}\text { 1. Linguagens e suas Tecno- } \\
\text { logias, } \\
\text { 2. Matemática e suas Tecno- } \\
\text { logias, } \\
\text { 3. Ciências da Natureza e } \\
\text { suas Tecnologias, } \\
\text { 4. Ciências Humanas e Soci- } \\
\text { ais aplicadas. }\end{array}$ & $\begin{array}{l}\text { 1. Língua Portuguesa, } \\
\text { 2. Matemática. }\end{array}$ & $\begin{array}{l}\text { 1. Língua Portuguesa, } \\
\text { Arte, Educação Física e } \\
\text { Língua inglesa. } \\
\text { 2. Matemática; } \\
\text { 3. Biologia, Física e Quí- } \\
\text { mica } \\
\text { 4. História, Geografia, So- } \\
\text { ciologia e Filosofia; }\end{array}$ & $\begin{array}{l}\text { Conjunto de apren- } \\
\text { dizagens essenciais } \\
\text { para desenvolvi- } \\
\text { mento de todos os } \\
\text { estudantes do En- } \\
\text { sino Médio. }\end{array}$ \\
\hline
\end{tabular}

Fonte: Adaptada pelo autor baseado na BNCC (2018).

Posteriormente à breve apresentação sobre como se divide e se organiza a BNCC na etapa do Ensino Médio e de como autores de diferentes áreas se posicionam diante 
desse documento organização, conforme dito anteriormente, focalizaremos no que o documento versa para a área de Linguagens e suas Tecnologias, especificamente sobre a produção textual e as tecnologias digitais, no intuito de contemplar os temas que são objetos do nosso estudo. É importante destacar que a área de Linguagens e suas tecnologias está organizada em volta de cinco campos de atuação social, a saber: campo da vida social, das práticas de estudo e pesquisa, jornalístico-midiático, de atuação na vida pública e do campo artístico.

Contudo, um fato que chama a atenção na BNCC, é o tratamento dado a temática das Tecnologias Digitais de uma maneira geral. Conforme Mendonça e Soares (2019), as relações de aprendizagem por meio das tecnologias digitais ganham uma abordagem ampliada no documento como um todo. Constatamos que, quando a BNCC apresenta as habilidades a serem desenvolvidas pelas áreas em todas as etapas da Educação básica, as tecnologias digitais são sugeridas como meio de aprendizagem do conteúdo abordado, porém, ao serem especificadas as habilidades, em alguns casos verificamos que as tecnologias digitais tendem a ser utilizadas como ferramentas, reduzindo, assim, a sua capacidade de potencialização da aprendizagem. Mais adiante apontaremos esses casos como exemplificação do que estamos chamando a atenção.

Mendonça e Soares (2019) apontam que ao apreciarmos o documento na sua parte inicial é possível verificar que o tema "tecnologias digitais" compõe uma das dez competências gerais e perpassa por outras três competências que tratam o digital como uma das linguagens a serem utilizadas aprofundando o seu uso na concepção crítica de Freire ([1970] 1987. Para nós, o fato do tema "tecnologias digitais" compor as competências gerais do documento demonstra que a objetificação da BNCC é que estas sejam reconhecidas como um eixo norteador de novas práticas pedagógicas, reforçando o caráter transdisciplinar do tema.

Conforme dito anteriormente, a Base estabelece o tema como uma das dez competências gerais $\left(n^{\circ} 5\right)$ e perpassa por outras três competências ( $n^{\circ} 1,2$ e 4) para a Educação Básica, propondo que a sua utilização ocorra de forma bem ampla e de maneira transversal. No Quadro 2, adiante, visualizaremos melhor o que o documento propõe: 
Quadro 2 - Apresentação das competências gerais da Educação Básica sobre o tema "Tecnologias Digitais"

\begin{tabular}{|c|l|}
\hline \multicolumn{2}{|c|}{ O tema “Tecnologias Digitais" nas Competências Gerais da Educação Básica } \\
\hline Competência no & \multicolumn{1}{c|}{ O que diz } \\
\hline $\mathbf{1}$ & $\begin{array}{l}\text { Valorizar e utilizar os conhecimentos historicamente construídos sobre o } \\
\text { mundo físico, social, cultural e digital para entender e explicar a realidade, } \\
\text { continuar aprendendo e colaborar para a construção de uma sociedade justa, } \\
\text { democrática e inclusiva. }\end{array}$ \\
\hline $\mathbf{2}$ & $\begin{array}{l}\text { Exercitar a curiosidade intelectual e recorrer à abordagem própria } \\
\text { das ciências, incluindo a investigação, a reflexão, a análise crítica, a imagina- } \\
\text { ção e a criatividade, para investigar causas, elaborar e testar hipóteses, for- } \\
\text { mular e resolver problemas e criar soluções (inclusive tecnológicas) com base } \\
\text { nos conhecimentos das diferentes áreas. }\end{array}$ \\
\hline $\mathbf{4}$ & $\begin{array}{l}\text { Utilizar diferentes linguagens - verbal (oral ou visual-motora, como Libras, } \\
\text { e escrita), corporal, visual, sonora e digital -, bem como conhecimentos das } \\
\text { linguagens artística, matemática e científica, para se expressar e partilhar in- } \\
\text { formações, experiências, ideias e sentimentos em diferentes contextos e pro- } \\
\text { duzir sentidos que levem ao entendimento mútuo. }\end{array}$ \\
\hline $\mathbf{5}$ & $\begin{array}{l}\text { Compreender, utilizar e criar tecnologias digitais de informação e comunica- } \\
\text { ção de forma crítica, significativa, reflexiva e ética nas diversas práticas soci- } \\
\text { ais (incluindo as escolares) para se comunicar, acessar e disseminar informa- } \\
\text { ções, produzir conhecimentos, resolver problemas e exercer protagonismo } \\
\text { e autoria na vida pessoal e coletiva. }\end{array}$ \\
\hline
\end{tabular}

Fonte: Produzido pelas autoras com base na BNCC (BRASIL, 2018).

Diante do quadro apresentado acima, podemos afirmar que na competência de $n^{\circ}$ 5 está explícito que a BNCC reconhece o potencial das tecnologias digitais como instrumento facilitador da construção do conhecimento, evidenciando-as como objeto de ensino. Borges da Silva (2019) afirma que:

O item 5 evidencia as TDIC como objeto de ensino, quando ressalta como competência a ser desenvolvida e não somente sua compreensão e utilização, mas também lhe concede um papel importante no processo criativo, visto que preconiza a criação de tecnologias. (BORGES DA SILVA, 2019, p. 200)

A autora indica, desse modo, ser possível inferir que "as metodologias inovadoras estariam implicadas nesse processo criativo, contemplado pela competência", significando 
que “as tecnologias não estão na escola apenas como dispositivos a serem consumidos, mas como possibilidades inventivas” (BORGES DA SILVA, 2019, p. 200).

Sobre as demais competências, visualizamos a tentativa de demonstrar a sua amplitude dentro da sociedade atual, ao reconhecer que as tecnologias digitais modificaram as nossas formas de comunicação e consequentemente a nossa maneira de estar no mundo.

A BNCC (2018) adota o digital como uma nova linguagem e indica que as tecnologias digitais sejam o alicerce das práticas pedagógicas a serem desenvolvidas fundamentadas neste documento, "delineando um cenário favorável às práticas docentes inovadoras" (BORGES DA SILVA, 2019, p. 200). A seguir, destacamos um dos trechos do documento que versa sobre a temática:

Há que se considerar, ainda, que a cultura digital tem promovido mudanças sociais significativas nas sociedades contemporâneas. Em decorrência do avanço e da multiplicação das tecnologias de informação e comunicação e do crescente acesso a elas pela maior disponibilidade de computadores, telefones celulares, tablets e afins, os estudantes estão dinamicamente inseridos nessa cultura, não somente como consumidores. Os jovens têm se engajado cada vez mais como protagonistas da cultura digital, envolvendo-se diretamente em novas formas de interação multimidiática e multimodal e de atuação social em rede, que se realizam de modo cada vez mais ágil. (BRASIL, 2018, p. 61)

Na etapa do Ensino Médio, podemos inferir que a temática “tecnologias digitais" perpassam por duas ( $\mathrm{n}^{\circ} 1$ e 7 ) das sete competências específicas da área de Linguagens e suas Tecnologias, conforme demonstraremos no Quadro 3, seguinte:

Quadro 3 - Apresentação das competências específicas de linguagens para a etapa do Ensino Médio

\begin{tabular}{|l|}
\hline \multicolumn{1}{|c|}{ Competências específicas de linguagens do Ensino Médio } \\
\hline 1. Compreender o funcionamento das diferentes linguagens e práticas culturais (artísticas, corporais e ver- \\
bais) e mobilizar esses conhecimentos na recepção e produção de discursos nos diferentes campos de atu- \\
ação social e nas diversas mídias, para ampliar as formas de participação social, o entendimento e as possi- \\
bilidades de explicação e interpretação crítica da realidade e para continuar aprendendo. \\
\hline 7. Mobilizar práticas de linguagem no universo digital, considerando as dimensões técnicas, críticas, criati- \\
vas, éticas e estéticas, para expandir as formas de produzir sentidos, de engajar-se em práticas autorais e \\
coletivas, e de aprender a aprender nos campos da ciência, cultura, trabalho, informação e vida pessoal e \\
coletiva.
\end{tabular}

Fonte: Elaborado pela pesquisadora. 
Diante do quadro 3, exposto anteriormente, verificamos que a temática passa a ter um alcance maior, pois estas competências específicas atravessam os componentes da área, possibilitando o desenvolvimento pedagógico de maneira diversificada. $\mathrm{Na}$ competência $\mathrm{n}^{\circ}$ 1, sugere-se a utilização de diversas mídias e isso perpassa pela Cultura digital e na competência $\mathrm{n}^{\circ} 7$ temos a utilização das tecnologias digitais como possibilidade de desenvolvimento de competências e habilidades próprias do século XXI.

Devemos salientar que apesar de encontramos um documento em consonância com o nosso estudo, que acredita nas tecnologias digitais como elemento facilitador do ensino e da aprendizagem, nossa análise chama a atenção para a necessidade de um trabalho que alcance traços de criatividade com caráter colaborativo, como previsto nas competências gerais. Acreditamos que a utilização das tecnologias digitais como elemento ilustrador apenas “ajudam na condução da aula, ilustram, animam" (ALVES, 1998, p. 145). Conforme Alves (1998) alerta, “os conceitos de instrumento e ferramenta limitam bastante o potencial dos elementos tecnológicos no contexto social e em especial no ambiente escolar, pois nesta perspectiva a tecnologia termina sendo usada para modelar o pensar humano" (ALVES, 1998, p. 146).

Especificamente, ao observarmos as habilidades descritas para a competência específica de $\mathrm{n}^{\circ} 7$, poderemos ilustrar nossa discussão. Nessa competência temos descritas quatro habilidades. A primeira habilidade (EM13LGG701) diz respeito a exploração das funcionalidades das tecnologias digitais; a segunda (EM13LGG702), sugere-se o uso crítico das tecnologias digitais para avaliar os seus impactos na formação dos sujeitos; a terceira habilidade (EM13LGG703), trata sobre a utilização e produção dos diversos tipos de linguagens e a última habilidade (EM13LGG704) diz respeito a apropriação crítica dos processos de pesquisa e busca de informação na Internet. Nesse sentido, os processos de re(criação) de forma colaborativa precisam ser reconhecidos como parte fundamental na educação.

Ainda sobre o Ensino Médio e a Língua Portuguesa, o documento propõe quatro eixos: Leitura, Produção de Textos (orais, escritos, multissemióticos), Oralidade e Análise 
Linguística/Semiótica (componente novo em relação aos parâmetros curriculares). A inclusão dessa área indica, mais uma vez, que o documento busca contemplar as tecnologias digitais e as múltiplas linguagens que compõem os textos produzidos na Cibercultura.

Veremos na BNCC (2018), na seção de Língua Portuguesa do Ensino Médio, que ganham destaques "práticas contemporâneas de linguagem" como a "cultura digital, os novos letramentos e os multiletramentos" (BRASIL, 2018, p. 490). Observamos que o documento propõe o uso de uma variedade de recursos digitais e textos que permeiam a esfera digital. Encontraremos, por exemplo, a sugestão para produção de vlogs, podcast, playlist comentadas (BRASIL, 2018, p. 509). Encontraremos também a orientação para produção e compartilhamento nas redes sociais e ou em outros ambientes digitais de memes e gifs (BRASIL, 2018, p. 522).

Salientamos que todos esses gêneros fazem parte do universo cultural dos alunos do Ensino Médio e o fato do documento oficial abarcar esses gêneros traz a oportunidade de um trabalho efetivo para o desenvolvimento da produção textual. Contudo, conforme Marchuschi (2002), para Bronckart (1999) “a apropriação dos gêneros textuais é um mecanismo fundamental de socialização, de inserção prática nas atividades comunicativas humanas" (BRONCKART, 1999 apud MARCHUSCHI, 2002, p. 24); assim, dominar um gênero é "uma forma de realizar linguisticamente objetivos específicos em situações sociais particulares" (MARCHUSCHI, 2002, p. 24), o que nos permite afirmar que, se o aluno tiver contato com o maior número de gêneros textuais possíveis, isso fará como que ele amplie seu conhecimento de mundo, isso consequentemente refletirá no seu modo de estar no mundo socialmente e também no seu processo de escrita, uma vez que nos situamos no mundo através da linguagem.

Entretanto, no momento em que a BNCC prescreve o que deve ser ensinado em Língua Portuguesa, precisamos estar atentos à forma e ao contexto em que as tecnologias digitais serão utilizadas para que possam favorecer práticas que valorizem o seu caráter criativo e colaborativo e que tragam significações para além do desenvolvimento de habilidades. 
Na Figura 2, a seguir, temos uma amostra da necessidade do cuidado com o uso das tecnologias digitais, nos quadros que definem as competências e habilidades específicas.

Figura 2 - Quadro de habilidades e competências específicas por campo de atuação social

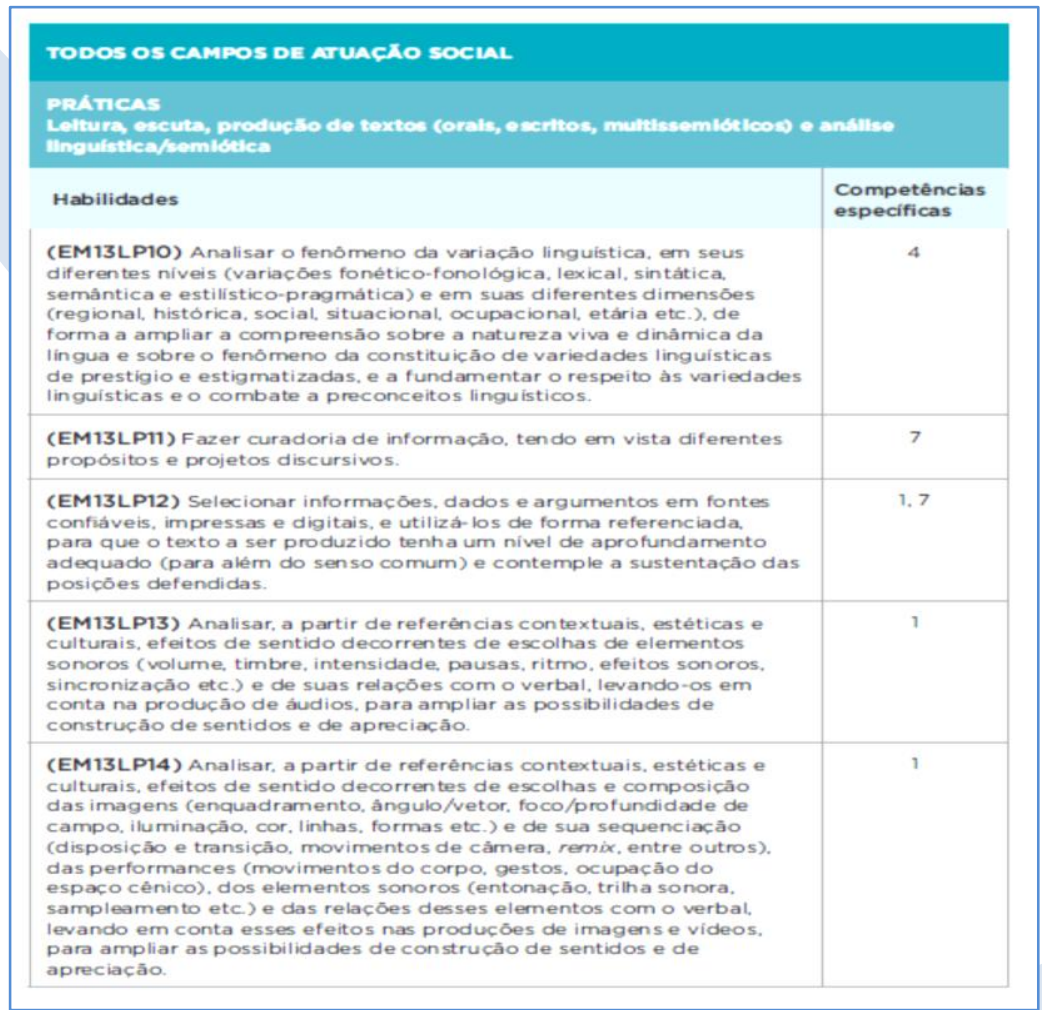

Fonte: BNCC (BRASIL, 2018, p. 508).

Observamos que nas seções de descrições das habilidades a serem alcançadas temos a utilização de verbos de ação, como fazer, analisar e selecionar, que indica a orientação a ser seguida, mas podemos vislumbrar a possibilidade de uma ação mais criativa que permitiria o desenvolvimento, em maior amplitude, das habilidades de acordo com o exemplo da Figura 2. 
Sendo assim, ao transpor essas orientações para a sala de aula é preciso cuidado para não utilizarmos a tecnologia somente como recurso recreativo. Talvez, ousamos dizer, que antes de seguir as orientações da base, precisaremos passar por um processo amplo de formação do professor em relação as tecnologias digitais.

Ademais, torna-se relevante esse nosso breve olhar para a BNCC, no sentido de compreender quais as perspectivas governamentais para o nosso fazer pedagógico.

\section{Conclusão}

Em virtude dos avanços tecnológicos em nosso cotidiano, do cenário atual educacional, o nosso estudo se mostra relevante no que tange sua proposta de apresentar uma breve reflexão em torno das orientações presentes na Base Nacional Curricular Comum, em relação ao uso das tecnologias digitais na sala de aula e a produção textual.

Sabemos que contemporaneidade modificou as relações dos alunos com o texto, com a escrita, multiplicou as linguagens, sendo possível que a escola incorpore essa nova realidade. Assim, verificamos como nosso estudo, que apesar da BNCC ter seu caráter prescritivo, ela busca inserir no contexto escolar as novas linguagens que permeiam nosso cotidiano e que isso pode contribuir para a inserção das tecnologias digitais na sala de aula.

É interessante apontar que no intuito de proporcionar uma mudança de realidade na prática de ensino da produção textual e também na formação desse aluno, devemos procurar a aproximação da escrita com a realidade social, promovendo a inserção, buscando dar sentido para sua escrita (MENDONÇA; SOARES, 2018). Promover diversas formas de aproximação com o mundo atual permite ao aluno dialogar, se expressar em diferentes linguagens, desenvolvendo assim as competências requeridas para o incremento da escrita.

Dessa maneira, a produção da escrita, no contexto escolar, deve criar situações em que os alunos sejam estimulados a produzir novos sentidos por meio da linguagem que permeia o seu contexto social, mas para isso, como foi dito anteriormente precisamos promover uma formação ampla do professor de maneira que ele perceba o potencial que a 
utilização das tecnologias digitais possuem para o desenvolvimento dos seus alunos. É importante frisar que o uso das tecnologias digitais pode contribuir para que tenhamos aulas mais criativas, interativas e colaborativas e o professor deve se apropriar dessa potência.

Portanto, entendemos que para essa implantação das tecnologias digitais é fundamental que se assuma o que está estabelecido nas competências gerais da BNCC. Que se aproprie-se do digital como uma das linguagens a serem empregadas na sala de aula, aprofundando as discussões do seu uso na concepção crítica e como um elemento importante para criação de novas práticas pedagógicas.

Precisamos reconhecer os novos modos, os novos eventos de letramentos e integrá-los à nossa prática diária.

\title{
A BRIEF LOOK AT BNCC, DIGITAL TECHNOLOGIES AND TEXTUAL PRODUCTION IN HIGH SCHOOL
}

\begin{abstract}
Cyberculture is a reality that is increasingly part of our society, transforming it constantly and quickly. Thus, the insertion of digital technologies in pedagogical practice and in the school environment is necessary in a way that allows students to build knowledge based on collaborative practices. This text aims to demonstrate a small analysis around the guidelines contained in the National Common Curricular Base, hereinafter BNCC, with regard to the use of digital technologies in the classroom, focusing on textual production in high school. Qualitative, this work is characterized from the perspective of documentary research and theoretical studies in the light of authors such as Alves (1998), Bohn (2013), Lévy (2010) and Marcuschi, (2004). The results indicate that the BNCC recommends that digital technologies be assumed as a relevant element for the elaboration of new pedagogical practices.
\end{abstract}

KEYWORDS: BNCC, Digital Technologies, Textual Production.

\section{REFERÊNCIAS}

ALVES, Lynn Rosalina Gama. Novas Tecnologias: instrumento, ferramenta ou elementos estruturantes de um novo pensar? Revista da FAEEBA, Salvador, p. 141-152, 1998.

ANTUNES, Irandé. Práticas pedagógicas para o desenvolvimento da escrita. In: COELHO, Fábio André; PALOMANES, Roza (Org.). Ensino da Produção Textual. - São Paulo: Contexto, 2016. p. 9-21.

BAKHTIN, Mikhail Mikhailovitch. Marxismo e filosofia da linguagem: problemas fundamentais do método sociológico na ciência da linguagem. São Paulo: Hucitec, 1981. 
BAKHTIN, Mikhail Mikhailovitch (1979). Estética da criação verbal. Tradução de Maria Ermantina Galvão Gomes Pereira. 2. ed. São Paulo: Martins Fontes, 1997.

BRASIL. Base Nacional Comum Curricular: Educação é a Base. Brasília: MEC/Secretaria de Educação Básica, 2018. Disponível em: http://basenacionalcomum.mec.gov.br/images/BNCC_EI_EF_110518_versaofinal_site.pdf. Acesso em: 10 maio 2019.

BARTON, David; LEE, Carmen. Linguagem online: textos e práticas digitais. Tradução Milton Camargo Mota. 1. ed. São Paulo: Parábola Editorial, 2015.

BOHN, Hilário. BOHN, Hilário I. Ensino e aprendizagem de línguas: os atores da sala de aula e a necessidade de rupturas. Linguística aplicada na modernidade recente: festschrift para Antonieta Celani. São Paulo: Parábola, v. 1, p. 79-98, 2013.

BORGES DA SILVA, Simone Bueno. Língua e tecnologias de aprendizagem na escola. In: FERRAZ, Obdália (Org.). Educação, (multi)letramentos e tecnologias: tecendo redes de conhecimento sobre letramentos, cultura digital, ensino e aprendizagem na cibercultura. Salvador: EDUFBA, 2019. p. 189-204.

BRITO, Percival Leme. Em terra de surdos-mudos (um estudo sobre as condições de produção de textos escolares). Trabalhos em linguistica aplicada, v. 2, 1983.

BUNZEN, Clécio. Da era da composição à era dos gêneros: o ensino de produção de texto no ensino médio. In: BUNZEN, Clécio; MENDONÇA, Márcia. (Org.). Português no ensino médio e formação do professor. São Paulo: Parábola Editorial, 2006. p. 139-161.

CURY, Carlos Roberto Jamil; REIS, Magali; ZANARDI, Teodoro Adriano Costa. Base Nacional Comum Curricular: dilemas e perspectivas. São Paulo: Cortez, 2018.

DUDENEY, Gavin; HOCKLY, Nicky; PEGRUM, Mark. Letramentos digitais. Trad. Marcos Marcionilo. São Paulo: Parábola Editorial, 2016.

ELIAS, Vanda Maria. Escrita e práticas comunicativas na internet. In: ELIAS, Vanda Maria (Org.). Ensino de Lingua Portuguesa: oralidade, escrita e leitura. São Paulo: Contexto, 2011. p. 159-166.

EMEDIATO, Wander. Aspectos lógicos, críticos e Linguísticos do ensino da leitura e escrita. In: CAMPOS, Lucas; MEIRA, Vivian (Org.). Teorias Linguísticas e aulas de português. Salvador: EDUNEB, 2016. p. 143-176.

FREIRE, Paulo. Pedagogia do oprimido. 17. ed. Rio de Janeiro: Paz e Terra, 1987.

HETKOWSKI, Tania Maria; MENEZES, Catia Neri. Prática de multiletramentos e tecnologias digitais: múltiplas aprendizagens potencializadas pelas tecnologias digitais. In: Educação, (multi)letramentos e tecnologias: tecendo redes de conhecimento sobre letramentos, cultura digital, ensino e aprendizagem/ Obdalia Ferraz, organizadora - Salvador: EDUFBA, 2019. p. 205-230 
LÉVY, Pierre. Cibercultura. Tradução de Carlos Irineu da Costa. 3. ed. São Paulo: Editora 34, 2010.

LOPES, Alice Casimiro. Itinerários formativos na BNCC do Ensino Médio: identificações docentes e projetos de vida juvenis. Revista Retratos da Escola, Brasília, v. 13, n. 25, p. 59-75, jan./mai. 2019. Disponível em: http://retratosdaescola.emnuvens.com.br/rde/issue/view/35. Acesso em: 12 março de 2019

MARCUSCHI, Luiz António. Gêneros textuais: definição e funcionalidade. In: DIONÍSIO, A.; MACHADO, A. R.; BEZERRA, M. A. (Org.). Gêneros textuais e ensino. Rio de Janeiro: Lucerna, 2002. p. 19-38.

MARCUSCHI, Luiz António. Hipertexto e gêneros digitais: novas formas de construção do sentido. Luiz Antônio Marcuschi, Antônio Carlos dos Santos Xavier (Org.). Rio de Janeiro: Lucerna, 2004.

MARINHO-ARAUJO, Claisy Maria; ALMEIDA, Leandro S. Abordagem de competências, desenvolvimento humano e educação superior. Psic.: Teor. e Pesq., Brasília, v. 32, n. spe, e32ne212, 2017. Disponível em: http://www.scielo.br/scielo.php?script=sci_arttext\&pid=S0102-37722016000500211\&lng=pt\&nrm=iso. Acesso em: 27 maio 2019. http://dx.doi.org/10.1590/0102-3772e32ne212.

MENDONÇA, Fernanda de Quadros C; SOARES, Claudia Vivien C de Oliveira. O uso de tecnologias digitais na sala de aula: contribuições para o ensino e aprendizado da produção textual nos anos finais do ensino fundamental. In: Lingua, texto e ensino: descrições e aplicações. 1ed. Vitória da Conquista: Pipa Comunicação, 2018, v.1, p. 1109-1114.

MENDONÇA, Fernanda de Quadros C; SOARES, Claudia Vivien C de Oliveira. Tecnologias digitais na sala de aula: um breve olhar para a BNCC. IN: XIII COLÓQUIO DO MUSEU PEDAGÓGICO. Anais... Vitória da Conquista, 2019, v.13, p. 2764 - 2768.

PRETTO, Nelson de Luca. Redes sociais e educação: o que quer a geração alt + tab nas ruas? Liinc em Revista, v. 10, n.1, 2014. Disponível em: http://revista.ibict.br/liinc/article/view/3498. Acesso em: 10 maio 2019.

RIBEIRO, Ana Elisa. Textos multimodais: leitura e produção. 1. ed. São Paulo: Parábola Editorial, 2016.

SANTAELLA, L. A aprendizagem ubíqua na educação aberta. Revista Tempos e Espaços em Educação, São Cristóvão, v. 7, n. 14, p. 15-22, set./dez. 2014. Disponível em: https://seer.ufs.br/index.php/revtee/article/view/3446/3010. Acesso em: 20 set. 2017

SANTOS, Fernanda Maria Almeida dos. Multiletramentos e ensino de língua portuguesa na educação básica: uma proposta didática para o trabalho com (hiper)gêneros multimodais. Signo, Santa Cruz do Sul, v. 43, n. 76, p. 55-65, jan. 2018. ISSN 1982-2014. Disponível em: https://online.unisc.br/seer/index.php/signo/article/view/10671. Acesso em: 10 maio 2019. 
SILVA, Mônica Ribeiro da. A BNCC da reforma do ensino médio: o resgate de um empoeirado discurso. EDUR - Educação em Revista. 2018. Disponível em: http:/ /www.scielo.br/pdf/edur/v34/1982-6621-edur-34-e214130.pdf. Acesso em: 10 mar. 2019.

SILVA, Zenilda Ribeiro da. Os gêneros textuais digitais e o ensino da lingua portuguesa: o facebook como ferramenta pedagógica para o desenvolvimento da escrita. 120 f. 2015. Dissertação (Mestrado) - Centro de Formação de Professores, Curso de Mestrado Profissional em Letras, Universidade Federal de Campina Grande, Cajazeiras, Paraíba, 2015. Disponível em: http://dspace.sti.ufcg.edu.br:8080/jspui/handle/riufcg/205. Acesso em: 01 ago. 2019.

VYGOTSKY, Lev Semenovich. A formação social da mente brasileira. 4. ed. São Paulo: Livraria Martins Fontes Editora, 1991.

Recebido em: 29/05/2020.

Aprovado em: 20/06/2020. 